\title{
Introduction: First International Workshop on Enabling Service Business Ecosystems (ESBE 2008)
}

This part of this volume contains the proceedings of the First International Workshop on Enabling Service Business Ecosystems (ESBE'08), held on December 01, 2008 in Sydney, Australia, in conjunction with the International Conference on Service Oriented Computing (ICSOC) 2008.

Today, services are used as a core component or utility of business operations and offer programmatic interfaces to applications to exploit these services. The majority of attention on service oriented systems has been contemplated on its related technical standards and technology integration. However, many of today's available services are not considered as providing relevant business value as their use by third-party clients have unclear terms and conditions with unknown risk. The trend of software transforming to the service oriented paradigm demands a new way of business model reassurance to manage services operation, deployment, and longevity in the context of business ecosystems.

The ESBE workshop aims to bring together researchers and practitioners in services development across business domains. Its focus is on creating business value through services and, looking beyond individual businesses, fostering the growth of a service ecosystem.

This year 6 papers were selected in two categories, 4 full research papers and 2 short research papers, based on a thorough review process, in which each paper was reviewed by at least 3 experts in the field. The selected papers illustrate very high caliber research in the field of service ecosystem.

We would like to take this opportunity to express our thanks to all people who have contributed to ESBE'08. We are indebted to all members of the program committee for their reviews and comments. We appreciate the opportunity given by the ICSOC workshop chairs to organize this workshop in conjunction with ICSOC 2008.

We hope you find the papers in this proceedings interesting and stimulating.

Vincenzo D'Andrea

G.R. Gangadharan

Renato Iannella

Michael Weiss 